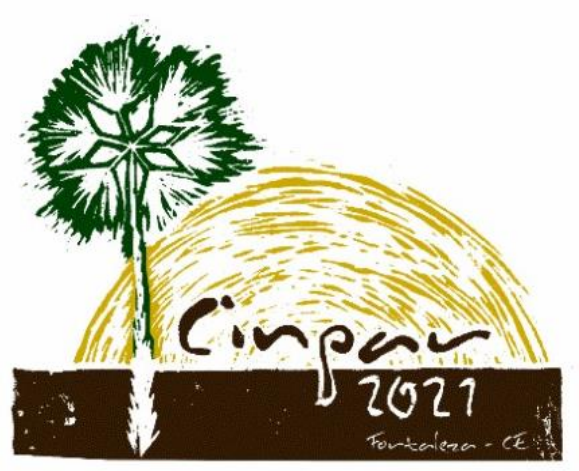

XVII Congresso Internacional sobre Patologia e

Reabilitação das Construções

XVII Congreso Internacional sobre Patología y Rehabilitación de las Construcciones

XVII International Conference on Pathology and Constructions Rehabilitation

FORTALEZA (Brasil), 3 a 5 de junho de 2021

https://doi.org/10.4322/CINPAR.2021.099

\title{
Análise da umidade e da salinidade em paredes de alvenaria
}

\section{Analysis of humidity and salinity in masonry walls}

\author{
Letícia N. C. CAVALCANTI ${ }^{1}$, Roberta S. MARTINS ${ }^{2}$, Anderson H. BARBOSA
}

\footnotetext{
${ }^{1}$ Universidade Federal do Vale do São Francisco, Juazeiro-BA, Brasil, leticianovcunha@gmail.com

2 Universidade Federal do Vale do São Francisco, Juazeiro-BA, Brasil, robertamartins.s@outlook.com

${ }^{3}$ Universidade Federal do Vale do São Francisco, Juazeiro-BA, Brasil, anderhb80@gmail.com
}

\begin{abstract}
Resumo: Nas edificações são frequentes o surgimento de manifestações patológicas, dentre as mais comuns estão as relacionadas à presença de umidade e salinidade em locais indesejados. Nesse contexto, esta trabalho tem como objetivo avaliar a influência da umidade e do sal em paredes de alvenaria de blocos cerâmicos revestidos de argamassa. Para este estudo, foram moldados prismas de dois blocos, revestidos com argamassa em ambas as faces (traço 1:4). Estes prismas foram inseridos em uma camada de solo saturado em duas soluções, uma com água e outra com água/sal, sendo metade destas amostras impermeabilizadas. Com exceção das amostras utilizadas como referência, os prismas foram expostos à 7 ciclos de molhagem e secagem. Ao final dos ciclos, todas as paredes foram submetidas ao ensaio de resistência à compressão e de aderência à tração. Percebeu-se com os ensaios, que a resistência mecânica dos prismas que estavam imersos em solução de água/sal obtiveram os valores menos satisfatórios, e que a camada lisa do impermeabilizante interferiu na aderência da argamassa.
\end{abstract}

Palavras-chave: Manifestação Patológica. Construção. Sal. Umidade.

\begin{abstract}
In buildings, pathological manifestations are frequent, among the most common are those related to the presence of humidity and salinity in unwanted places. In this context, this work aims to evaluate the influence of humidity and salt on masonry walls of ceramic blocks covered with mortar. For this study, two block prisms were molded, coated with mortar on both sides (1: 4 trace). These prisms were inserted in a soil layer saturated in two solutions, one with water and the other with wate/rsalt, half of these samples being waterproofed. With the exception of the samples used as a reference, the prisms were exposed to 7 wetting/drying cycles. At the end of the cycles, all walls were subjected to the compressive strength and tensile adhesion test. It was noticed with the tests, that the mechanical resistance of the prisms that were immersed in water/salt solution obtained the least satisfactory values, and that the smooth layer of the waterproofing agent interfered with the mortar adhesion.
\end{abstract}

Keywords: Pathologic Manifestations. Construction. Salt. Humidity.

\section{Introdução}

No amplo seguimento de obras na engenharia é percebida a frequente ocorrência de manifestações patológicas, sejam elas novas ou antigas. Tais problemas e vícios aparentes em construções podem provocar efeito estético desagradável aos usuários.

Dentre os danos mais frequentes, a responsável pela maior parte das manifestações patológicas construtivas são aquelas provocadas pela umidade, principalmente em alvenarias, como apontado pelo Conseil International du Bâtiment - CIB (CIB W86, 1993). 
A umidade e seus efeitos nas edificações pode comprometer tanto a sua integridade, que consequentemente irá diminuir o seu conforto higrotérmico, como também influenciar diretamente a proliferação de microrganismos nocivos à saúde humana.

Pode-se destacar que a ação principal e mais prolongada da umidade nas alvenarias tem origem na absorção de água existente no solo pelas fundações e pavimentos. A partir dessa absorção ocorre também a ascensão dos sais presente nos solos, que posteriormente provocarão o surgimento de manifestações patológicas.

Segundo Pedrotti (2015), a salinização de solos é um problema que vem aumentando em todo o mundo, sendo estimado que exista cerca de 1 a 5 bilhões de hectares de solos afetados por sais. No Brasil o problema é verificado em todo país, acontecendo especialmente na região Nordeste, onde aproximadamente $25 \%$ das áreas irrigadas foram salinizadas.

Baseado no fato apontado acima e na grande e notável ocorrência das manifestações patológicas em alvenarias decorrentes de infiltração por capilaridade pela presença de umidade e sais nos solos da região local de Juazeiro-BA, e fundamentada na escassez de informações, analisou-se a importância de estudo do tema.

Diante disso, essa pesquisa tem como objetivo avaliar a influência da umidade e do sal em paredes de alvenaria de blocos cerâmicos revestidos de argamassa, a partir da verificação da resistência à compressão e de aderência à tração, em prismas de 2 blocos argamassados, submetidos a ciclos de molhagem/secagem, comparados a uma amostra de referência.

\section{Referencial teórico}

\subsection{Origens da umidade e suas vias de acesso}

A forma como a umidade se manifesta nas edificações permite classificá-la de maneiras diversas. Podendo ser, segundo Thomaz (1989):

- Umidade resultante da produção dos componentes construtivos que são fabricados à base de ligantes hidráulicos.

- Umidade proveniente da execução da obra, onde durante a operação de umedecimento dos componentes de alvenaria, o teor de umidade é elevado a valores superiores à umidade higroscópica de equilíbrio.

- Umidade do solo, onde, se não houver impermeabilização eficiente entre o solo e a base da construção, a água ascenderá por capilaridade, tendo acesso aos seus componentes.

- Umidade do ar, em que a água proveniente da chuva ou da própria umidade presente no ar, é absorvida pelos materiais de construção antes mesmo de ser utilizado ou durante a vida da construção.

Verçoza (1991), de forma semelhante, classificou as formas de ação da água nas construções. Segundo ele, a umidade aparece principalmente proveniente da atmosfera, do solo, durante a execução da obra ou por meio de vazamentos em redes hidráulicas.

A umidade proveniente do solo, também denominada de umidade ascensional, ocorre por capilaridade devido as condições do solo e a falta de impermeabilização adequada da fundação, impedindo a progressão da água pelos canais capilares da alvenaria. Na umidade proveniente da atmosfera, decorrente da água das chuvas ou de ambientes altamente úmidos, ocorre a percolação ou pressão hidrostática através das fachadas ou telhados. Por outro lado, na umidade proveniente da construção, decorrente principalmente de concretos e argamassas, a água utilizada permanece nos poros dos materiais. Por fim, a umidade proveniente de vazamentos hidráulicos, no qual, segundo Verçoza (1991), "são vazamentos muito danosos para o bom desempenho esperado da edificação se não forem corrigidos rapidamente, em especial os vazamentos havidos abaixo da estrutura da moradia". 


\subsection{Processo de salinização nas construções de alvenaria}

Segundo Pedrotti (2015), o processo de salinização dos solos é típico de regiões áridas e semiáridas, normalmente resultante da associação de fatores diversos, como a formação geológica predominante na paisagem, a má distribuição das chuvas, a deficiência de drenagem e ainda, de acordo com Silva et al. (2011), devido à própria natureza física e química dos solos.

Conforme Henriques (1995), a salinidade presente no solo pode atingir a alvenaria até níveis mais elevados, cristalizando-se com a evaporação da água, podendo também ocorrer um aumento na ascensão capilar devido à redução na permeabilidade da água nos materiais.

Para Arendt (1995), muitos materiais são capazes de conter uma quantidade de sais em teor prejudicial a construção, como a areia ou a argila que constitui o tijolo. Ainda sobre o tijolo, de acordo com Mecha (1993), nestes podem vir a ocorrer agressões originárias do meio externo ou do próprio material, causando eflorescência.

No cimento também podem ser encontradas impurezas, de acordo com Uemoto (1984), os que contém um elevado teor de álcalis e de potássio podem se transformar em hidróxidos durante a reação de hidratação, e em contato com a água se transformam em carbonatos de sódio e de potássio, sendo muito solúveis em água. Além desses ainda pode ser encontrado, segundo Souza (1997), o dióxido de titânio, que na presença de água, após a cura do cimento, também pode causar eflorescência.

Além da salinidade decorrente do solo e dos materiais, existe ainda a salinidade proveniente do ar, no qual o vento exerce forte influência. Essa salinidade é mais comum em áreas litorâneas, onde a concentração de sais no ar é mais elevada. Pode ocorrer ainda, segundo Arendt (1995), que outros vêm da poluição, incluindo os gases e madeira que quando em combustão liberam dióxido de enxofre.

\subsection{Manifestações patológicas em alvenaria decorrentes da umidade}

No âmbito da construção civil, a umidade é usada como forma de definição para problemas relativos à água em seus mais variados estados, formas de manifestação e danos causados à edificação. Segundo Verçoza (1991), "a umidade não é apenas uma causa de manifestação patológica, ela age também como um meio necessário para que grande parte das problemas em construções ocorra. Ela é fator essencial para o aparecimento de eflorescências, ferrugens, mofo, bolores, degeneração das pinturas, de rebocos e até a causa de acidentes estruturais".

\subsubsection{Mancha}

Estruturas que estão constantemente sujeitas a umidade, se compostas de materiais de elevada absorção capilar, como no caso das alvenarias, e sem sistema de impermeabilização, tendem a apresentar problemas devido à infiltração. Dentre esses, as manchas são as manifestações mais recorrentes, e que, segundo Verçoza (1987), deterioram os materiais construtivos e desvalorizam a obra.

\subsection{2 - Eflorescência}

A eflorescência ocorre a partir da dissolução dos sais presentes no cimento e na cal, causados pela infiltração da água. Ela se apresenta comumente em superfícies porosas, como é o caso do tijolo e da argamassa que compõe as alvenarias. A água, em seu processo de evaporação, leva consigo os sais para a superfície, que em contato com o ar, reagem com o dióxido de carbono e se solidificam, formando manchas ou, a depender da situação, estalactites.

De acordo com Verçoza (1987), criptoeflorescência é a formação de salinas, semelhantes a eflorescência, onde os sais formam grandes cristais que se fixam no interior da estrutura e ao crescerem podem pressionar a massa, formando rachaduras e posterior desplacamento. Seus principais causadores são os sulfatos, que aumentam de volume ao receberem água, e estando numa camada próxima a superfície, provocam a desagregação dos materiais, causando trincas e rachaduras. 
O mofo, segundo Verçoza (1987), é causado por fungos vegetais que produzem enzimas ácidas que corroem os materiais constitutivos da alvenaria. Ele se desenvolve normalmente em ambientes úmidos, pouco ventilados e com pouca incidência de luz solar. Assim como a eflorescência e as manchas, é consequência da presença de infiltrações na alvenaria.

\subsection{5 - Degeneração do revestimento}

De acordo com Bauer (1994), o descolamento está entre os problemas mais comuns em revestimentos de argamassa, e pode acontecer principalmente de duas formas: por empolamento, devido a expansão da cal hidratada presente na argamassa; ou em placas, em consequência da falta de aderência entre a argamassa e a base de aplicação. $\mathrm{O}$ autor citado destaca ainda que os dois tipos de descolamento podem ou não vir acompanhados do esfarelamento da argamassa, a chamada pulverulência, originada pela presença do alto teor de cloretos que eliminam a adesividade entre as partículas da argamassa. A degeneração do revestimento implica em uma perda da resistência da alvenaria, visto que uma das funções do revestimento é a de vedação, dificultando a chegada de água e agentes nocivos à alvenaria.

\section{Metodologia}

\subsection{Execução das alvenarias}

Para a execução das alvenarias foram utilizados blocos cerâmicos de 09x19x19 cm com 8 furos, areia média e cimento do tipo CP II-F-32. As alvenarias foram executadas com a junção de 02 blocos, com argamassa de assentamento padrão para todas as amostras, de espessura $1 \mathrm{~cm}$, e revestidos com argamassa com traço 1:4 e espessura de $2 \mathrm{~cm}$ (chapisco + reboco), em ambas as faces, como pode ser conferido na Figura 1.

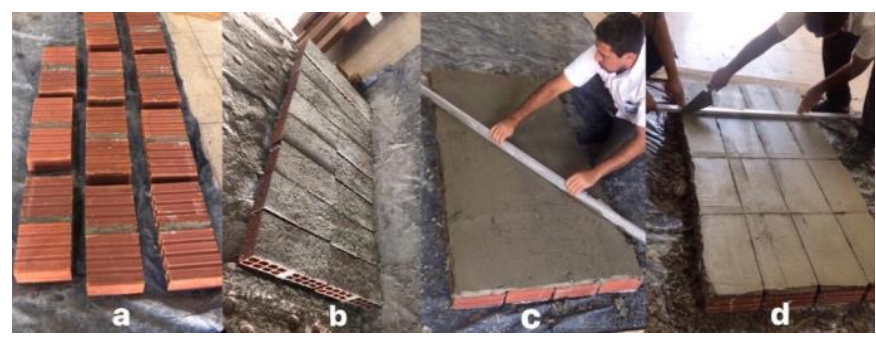

Figura 1 - Esquema de produção dos prismas

Da Figura 1, tem-se que: a) junção dos blocos com argamassa; b) chapiscamento das faces; c) sarrafeamento e desempolamento do reboco; d) corte dos prismas. Foram produzidos 24 prismas, sendo a metade destes destinados à impermeabilização com pintura asfáltica.

\subsection{Execução dos ensaios}

Após produzidos os prismas, estes foram submetidos à ciclos de molhagem e secagem, seguindo o procedimento:

a) Os prismas foram inseridos em camada de solo, com altura imersa da alvenaria de $5 \mathrm{~cm}$, sendo o solo saturado em água (Solução 1) e água + sal (Solução 2), por um período de 1 dia.

b) Retirados do solo, com o intuito de acelerar o processo de deterioração e simular o processo de desgaste real, os prismas foram colocados em estufa a uma temperatura de $\pm 100^{\circ} \mathrm{C}$, por um período de 1 dia.

c) Repetiu-se este procedimento por 7 ciclos.

Ao final dos 7 ciclos, os prismas foram submetidos aos seguintes ensaios: 
- Ensaio de resistência à compressão, conforme recomenda a NBR 15270-2/2017 (Componentes cerâmicos - Blocos e tijolos para alvenaria, Parte 2: Métodos de ensaio).

- Ensaio de resistência de aderência à tração, segundo a NBR 13528-3/2019 (Revestimento de paredes de argamassas inorgânicas - Determinação da resistência de aderência à tração, Parte 3: Aderência superficial).

\section{Resultados e discussões}

\subsection{Resistência à compressão}

Um total de 15 prismas foram submetidos ao ensaio de compressão. Na Tabela 1 estão apresentados as resistências obtidas.

Tabela 1 - Resultados obtidos com o ensaio de resistência à compressão

\begin{tabular}{|c|c|c|c|c|c|c|c|}
\hline Situação & $\mathrm{CP}$ & $\begin{array}{c}\mathrm{L} \\
(\mathrm{cm})\end{array}$ & $\begin{array}{c}\mathrm{H} \\
(\mathrm{cm})\end{array}$ & $\begin{array}{c}\mathrm{C} \\
(\mathrm{cm})\end{array}$ & $\begin{array}{l}\text { Carga de } \\
\text { ruptura } \\
(\mathrm{kN})\end{array}$ & $\begin{array}{c}\text { Resist. à } \\
\text { compressão } \\
(\mathrm{MPa})\end{array}$ & $\begin{array}{c}\mu \\
(\mathrm{MPa})\end{array}$ \\
\hline \multirow{3}{*}{ Referência } & CP 1 & 13,5 & 40 & 19 & 64,12 & 2,50 & \multirow{3}{*}{3,52} \\
\hline & $\mathrm{CP} 2$ & 13 & 40 & 18,5 & 92,35 & 3,84 & \\
\hline & $\mathrm{CP} 3$ & 13,5 & 40 & 18,5 & 105,35 & 4,22 & \\
\hline \multirow{3}{*}{$\begin{array}{c}\text { Imersos em } \\
\text { Solo + Solução } 1\end{array}$} & CP 1 & 13 & 40 & 20 & 78,29 & 3,01 & \multirow{3}{*}{4,06} \\
\hline & $\mathrm{CP} 2$ & 13,5 & 40 & 19 & 115,14 & 4,49 & \\
\hline & CP 3 & 13 & 40 & 19 & 115,77 & 4,69 & \\
\hline \multirow{3}{*}{$\begin{array}{c}\text { Imersos em } \\
\text { Solo + Solução } 2\end{array}$} & CP 1 & 13 & 40 & 19,5 & 73,91 & 2,92 & \multirow{3}{*}{3,15} \\
\hline & $\mathrm{CP} 2$ & 13 & 40 & 19,5 & 85,99 & 3,39 & \\
\hline & CP 3 & 13 & 40 & 19,5 & 79,46 & 3,13 & \\
\hline \multirow{3}{*}{$\begin{array}{c}\text { Imersos em } \\
\text { Solo + Solução } 1 \\
\text { (Impermeab.) }\end{array}$} & CP 1 & 13 & 40 & 19 & 108,18 & 4,38 & \multirow{3}{*}{3,69} \\
\hline & $\mathrm{CP} 2$ & 13 & 40 & 19 & 90,32 & 3,66 & \\
\hline & $\mathrm{CP} 3$ & 13,5 & 40 & 19,5 & 80,06 & 3,04 & \\
\hline \multirow{3}{*}{$\begin{array}{c}\text { Imersos em } \\
\text { Solo + Solução } 2 \\
\text { (Impermeab.) }\end{array}$} & CP 1 & 13 & 40 & 19 & 77,82 & 3,15 & \multirow{3}{*}{3,45} \\
\hline & $\mathrm{CP} 2$ & 13 & 40 & 19 & 85,49 & 3,46 & \\
\hline & CP 3 & 13 & 40 & 19 & 92,47 & 3,74 & \\
\hline
\end{tabular}

Comparando os dados da Tabela 1, foi observado que o valor médio da resistência dos prismas de referência resultaram menor em relação aos submetidos à imersão em solução 1, e maior em relação à solução 2 . Entende-se que o processo dos ciclos de molhagem/secagem podem ter acelerado a cura das paredes, contribuindo com a água necessária para hodratação do cimento, corroborando para uma elevação na resistência à compressão da argamassa.

Em relação aos primas com a adição de sal, a resistencia foi reduzida para as duas soluções (água e água+sal). Note-se, que, a presença da impermeabilização melhora a resistência por dificultar a ação do sal na alvenaria. Quando se observa a presença do sal na alvenaria, as amostras mergulhadas na solução com sal indicam redução da resistência pela presença do sal e dos ciclos. A presença do sal atua tanto no bloco cerâmico como na argamassa de assentamento e revestimento.

Comparadas as resistências quando no mesmo tipo de solução, de apenas água, diferindo apenas na impermeabilização, foi notado maior valor médio da resistência para os que estavam não impermeabilizados. Isso pode ser explicado, mais uma vez, pelo procedimento dos ciclos de secagem/molhagem terem potencializado a cura da argamassa utilizada na alvenaria. E, ainda, como a impermeabilização impede a entrada de água na estrutura, não foi possível obter o mesmo processo de cura para os prismas impermeabilizados. 
Por outro lado, os prismas imersos em solução 2 (água+sal), dentre os impermeabilizados e não impermeabilizados, desta vez, o maior valor de média ocorreu para os prismas impermeabilizados. Como já esperado, a impermeabilização contribuiu ao impedir a entrada por capilaridade da junção da umidade e do sal.

\subsection{Resistência de aderência à tração}

As Tabelas 2, 3 e 4 apresentam os resultados do ensaio de resistência de aderência a tração, conforme análise recomendada pela NBR 13528/2010.

Quadro 2 - Ensaio de resistência de aderência à tração dos prismas de referência.

\begin{tabular}{|c|c|c|c|c|c|c|c|c|c|c|}
\hline \multirow{2}{*}{$\mathrm{CP}$} & \multirow{2}{*}{$\begin{array}{c}\text { Фméd. } \\
(\mathrm{mm})\end{array}$} & \multirow{2}{*}{$\begin{array}{c}\text { Área } \\
\left(\mathrm{mm}^{2}\right)\end{array}$} & \multirow{2}{*}{$\begin{array}{c}\text { Carga de } \\
\text { ruptura (kgf) }\end{array}$} & \multirow{2}{*}{$\begin{array}{c}\text { Resistência } \\
\text { Ra (MPa) }\end{array}$} & \multicolumn{6}{|c|}{ Forma de ruptura (\%) } \\
\hline & & & & & Sub. & Sub/Chap & Chap. & Chap/Arg & Arg. & Arg/Cola \\
\hline 1 & \multirow{4}{*}{50} & \multirow{4}{*}{1963,50} & 140 & 0,70 & & & & 100 & & \\
\hline 2 & & & 206 & 1,03 & & & 100 & & & \\
\hline 3 & & & 83 & 0,41 & & & & 100 & & \\
\hline 4 & & & 157 & 0,78 & & & & 100 & & \\
\hline
\end{tabular}

Tabela 3 - Ensaio de resistência de aderência à tração dos prismas imersos em solo na Solução 1.

\begin{tabular}{|c|c|c|c|c|c|c|c|c|c|c|c|}
\hline & \multirow{2}{*}{$\mathrm{CP}$} & \multirow{2}{*}{$\begin{array}{c}\text { Фméd. } \\
(\mathrm{mm})\end{array}$} & \multirow{2}{*}{$\begin{array}{l}\text { Área } \\
\left(\mathrm{mm}^{2}\right)\end{array}$} & \multirow{2}{*}{$\begin{array}{c}\text { Carga de } \\
\text { ruptura (kgf) }\end{array}$} & \multirow{2}{*}{$\begin{array}{c}\text { Resistência } \\
\text { Ra (MPa) }\end{array}$} & \multicolumn{6}{|c|}{ Forma de ruptura (\%) } \\
\hline & & & & & & Sub. & Sub/Chap & Chap. & Chap/Arg & Arg. & Arg/Cola \\
\hline \multirow{8}{*}{ 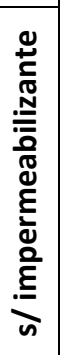 } & 5 & \multirow{8}{*}{50} & \multirow{8}{*}{1963,5} & 87 & 0,43 & & & & 100 & & \\
\hline & 6 & & & 140 & 0,70 & & & 100 & & & \\
\hline & 7 & & & 61 & 0,30 & & & & & & 100 \\
\hline & 8 & & & 146 & 0,73 & & & 100 & & & \\
\hline & 9 & & & 120 & 0,60 & & & & 100 & & \\
\hline & 10 & & & 126 & 0,63 & & & & 100 & & \\
\hline & 11 & & & 89 & 0,44 & & & & & 100 & \\
\hline & 12 & & & 144 & 0,72 & & & 100 & & & \\
\hline \multirow{8}{*}{ 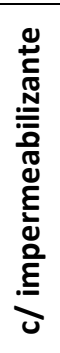 } & 13 & \multirow{8}{*}{50} & \multirow{8}{*}{1963,5} & 96 & 0,48 & & & & 100 & & \\
\hline & 14 & & & 67 & 0,33 & & & & 100 & & \\
\hline & 15 & & & 37 & 0,18 & & & & & 100 & \\
\hline & 16 & & & 51 & 0,25 & & & & & 100 & \\
\hline & 17 & & & 56 & 0,28 & & 100 & & & & \\
\hline & 18 & & & 39 & 0,19 & & & & & 100 & \\
\hline & 19 & & & 68 & 0,34 & & & & 100 & & \\
\hline & 20 & & & 115 & 0,57 & & & & 100 & & \\
\hline
\end{tabular}

Conforme exposto na Tabela 2, as amostras de referência apresentaram valores esperados de resistência, estando em conformidade com os limites mínimos exigidos na NBR 13749/1996 (Revestimento de paredes e tetos de argamassas inorgânicas - Especificação), que são de 0,20 MPa para paredes internas e 0,30 MPa para externas.

A partir dos dados da Tabela 3, nota-se que a maioria das rupturas aconteceu na interface chapisco/argamassa, o que seria um fator preocupante caso os valores de resistência fossem baixos, pois, segundo Carasek (2010), quando a ruptura é adesiva (ocorre nas interfaces), é necessário que os valores de resistência sejam mais elevados, uma vez que, neste caso, o potencial de ocorrência de manifestações patológicas futuras aumenta. 
Tabela 4 - Ensaio de resistência de aderência à tração dos prismas imersos em solo na Solução 2.

\begin{tabular}{|c|c|c|c|c|c|c|c|c|c|c|c|}
\hline & \multirow{2}{*}{$\mathrm{CP}$} & \multirow{2}{*}{$\begin{array}{l}\text { Фméd. } \\
(\mathrm{mm})\end{array}$} & \multirow{2}{*}{$\begin{array}{l}\text { Área } \\
\left(\mathrm{mm}^{2}\right)\end{array}$} & \multirow{2}{*}{$\begin{array}{c}\text { Carga de } \\
\text { ruptura (kgf) }\end{array}$} & \multirow{2}{*}{$\begin{array}{c}\text { Resistência } \\
\text { Ra (MPa) }\end{array}$} & \multicolumn{6}{|c|}{ Forma de ruptura (\%) } \\
\hline & & & & & & Sub. & Sub/Chap & Chap. & Chap/Arg & Arg. & Arg/Cola \\
\hline \multirow{8}{*}{ 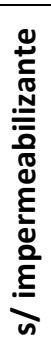 } & 21 & \multirow{8}{*}{50} & \multirow{8}{*}{1963,5} & 75 & 0,37 & & & & 100 & & \\
\hline & 22 & & & 78 & 0,39 & & & & & 100 & \\
\hline & 23 & & & 72 & 0,36 & & 100 & & & & \\
\hline & 24 & & & 62 & 0,31 & & & & & & 100 \\
\hline & 25 & & & 83 & 0,41 & & 100 & & & & \\
\hline & 26 & & & 51 & 0,25 & 20 & & 80 & & & \\
\hline & 27 & & & 38 & 0,19 & & & 100 & & & \\
\hline & 28 & & & 225 & 1,12 & & & & & 100 & \\
\hline \multirow{8}{*}{ 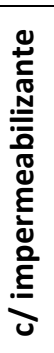 } & 29 & \multirow{8}{*}{50} & \multirow{8}{*}{1963,5} & 42 & 0,21 & & & & & 100 & \\
\hline & 30 & & & 62 & 0,31 & & 50 & 50 & & & \\
\hline & 31 & & & 71 & 0,35 & & & & 100 & & \\
\hline & 32 & & & 130 & 0,65 & & & & & 100 & \\
\hline & 33 & & & 46 & 0,23 & & 100 & & & & \\
\hline & 34 & & & 46 & 0,23 & & & & 100 & & \\
\hline & 35 & & & 56 & 0,28 & & 70 & 30 & & & \\
\hline & 36 & & & 45 & 0,22 & & 100 & & & & \\
\hline
\end{tabular}

Comparando os dados das Tabelas 3 e 4, é possível observar uma redução dos valores de resistência de aderência dos prismas impermeabilizados quando comparados aos sem impermeabilização, o que sugere uma interferência do impermeabilizante na aderência da argamassa. Pode ocorrer com a impermeabilização a interferência na cura da argamassa.

Alguns resultados apresentaram valores relativamente baixos, como exemplo das amostras 15,18 e 27 , que resultaram valores menores que 0,20 MPa, porém, de acordo com Carasek (2010), como a ruptura destes foi coesiva (ocorreram no interior da argamassa ou do chapisco), esses valores são menos preocupantes.

Segundo Carasek (2011), é comum que os resultados desse tipo de ensaio apresentem alta dispersão, resultando em coeficientes de variação da ordem de $10 \%$ a $35 \%$, mas chegam muitas vezes a $60 \%$, como foi observado nesse estudo e está apresentado na Tabela 5. Nesta, mostra a evidente influência tanto da umidade e do sal, assim como da impermeabilização, indicando que numa construção, os ciclos de absorção de umidade e secagem potencializam o surgimento de manifestações patológicas.

Tabela 5 - Valores estatísticos do ensaio de aderência

\begin{tabular}{|c|c|c|c|}
\hline & $\mu(\mathrm{MPa})$ & $\sigma(\mathrm{MPa})$ & $\mathrm{C} . \mathrm{V}(\%)$ \\
\hline Referência & 0,73 & 0,22 & 30,00 \\
\hline Solução 1 & 0,57 & 0,15 & 25,81 \\
\hline Solução 2 & 0,43 & 0,27 & 63,81 \\
\hline Solução 1 (Imperm.) & 0,33 & 0,13 & 38,56 \\
\hline Solução 2 (Imperm.) & 0,31 & 0,14 & 43,78 \\
\hline
\end{tabular}

\section{Conclusões}

De posse dos resultados, pode-se concluir que:

- A presença de umidade, e a consequente impermeabilização das alvenrias em regiões em contato com a água, apresentam interferência na resistência da alvenaria, o que contribui para o surgimento de manifestações patológicas ao longo do tempo nestes elementos construtivos. 
- Na avaliação da resistência à compressão, a presença de umidade contribuiu para acréscimo da resistência à compressão, ajudando à cura da argamassa potencializada pelo ciclo molhagem/secagem. A impermeabilização, impedidndo este fluxo de água, gerou decréscimos em relação à esta propriedade mecânica.

- A impermeabilização influenciou no ensaio de aderência, devido a camada lisa do impermeabilizante asfáltico, por isso, nos casos em que sejam necessários uma melhor aderência o uso de aditivo impermeabilizante para argamassas e concretos é uma opção mais vantajosa quando comparada à pintura asfáltica.

- Foram observados a rapidez e facilidade do surgimento da eflorescência nas amostras não impermeabilizadas, sendo percebido já nos primeiros ciclos de molhagem/secagem os vestígios da cristalização do sal, trazendo à tona a importância da impermeabilização.

\section{Referências Bibliográficas}

Arendt, C. (1995). Métodos de Tratamento de Alvenarias Deterioradas: Utilização de Rebocos de Recuperação e Medidas de Combate aos Sais. Porto Alegre: Universidade Federal do Rio Grande do Sul.

Associação Brasileira de Normas Técnicas. NBR 15270-1: Blocos cerâmicos para Alvenaria de Vedação Terminologia e Requisitos. Rio de Janeiro, 2005.

. NBR 13528: Revestimento de paredes de argamassas inorgânicas - Determinação da resistência de aderência à tração. Rio de Janeiro, 2010.

NBR 13749: Revestimento de paredes e tetos de argamassas inorgânicas - Especificação. Rio de Janeiro, 2013.

Bauer, L. A. F. Materiais de Construção. 5 ed. Rio de Janeiro: LTC, 1994.

Carasek, H. Guia de avaliação e interpretação de ensaios de sistemas de revestimento de argamassa. Comunidade da construção de Belo Horizonte. Belo Horizonte. 2011. 21 p. $4^{\circ}$ Ciclo.

. Argamassas. In: ISAIA, G. C. (Org.). Materiais de Construção Civil e Princípios de Ciência e Engenharia de Materiais. 2a ed. São Paulo - SP, v 2, 2010.

CIB WORKING COMMISSION W86. Building pathology: a state-of-the-art report. Rotterdam, The Netherlands: CIB, 1993. Henriques F. M. A. Umidade em paredes. Lisboa: Laboratório Nacional de Engenharia Civil, 1995.

Mecha, C. O. Patologia de la piedra y del ladrilho. Madrid: Serviço de publicaciones del colégio oficial de arquitectos de Madrid, 1993.

Pedrotti, A. Causas e consequências do processo de salinização dos solos. Revista Eletrônica em Gestão, Educação e Tecnologia Ambiental, Santa Maria, v. 19, n. 2, mai.-ago. 2015, p. 1308-1324.

Silva, J. L. A. et al. Evolução da salinidade em solos representativos do Agropólo Mossoró-Assu cultivado com meloeiro com água de deferentes salinidades. Agropecuária Científica no Semiárido, 2011.

Souza, G. F. Eflorescência nas argamassas de revestimento. Simpósio Brasileiro de Tecnologia das Argamassas. Salvador, 1997.

Thomaz, E. Trincas em edifícios: causas, prevenção e recuperação. 1. ed. São Paulo: Pini, 1989.

Uemoto, K. L. Patologia: Danos causados por eflorescência. Revista A Construção. São Paulo, 1984.

Verçoza, E. J. Impermeabilização na construçãol. 2 ed. Porto Alegre: Sagra,1987.

. Patologia das Edificações. Porto Alegre: Sagra, 1991. 